\title{
Escape into Culturally Safe Patient Centered Care
}

\section{Article History}

Received: 15 February, 2021

Revised: 31 March, 2021

Accepted: 08 April, 2021

Published: 15 April, 2021

Copyright $\odot 2021$ Noble Academic Publisher \& Author

\author{
Prasha Sooful* \\ Allied Health Directorate, Top End Health Service, Darwin Australia
}

\author{
Alex Hogan \\ Allied Health Directorate, Top End Health Service, Darwin Australia \\ Justine Williams \\ Allied Health Directorate, Top End Health Service, Darwin Australia \\ Renae Moore \\ Allied Health Directorate, Top End Health Service, Darwin Australia
}

\begin{abstract}
Collaboration and interprofessional practice between allied health professionals based in rural and remote regions of the Northern Territory are essential for Aboriginal patient health outcomes and reduced hospital admission rates. Training content that is relevant and promotes interprofessional practice allows for the cost effective and time efficient professional development of numerous employees in a single training course. An "escape room" format workshop was trialed for the Katherine region and the community allied health workforce. The escape room was a unique way to improve interprofessional collaboration for an isolated workforce and improve professionals' knowledge on the organisation's principles of patient centered care. There was an overwhelmingly positive response from participants who enjoyed the novelty of this professional development activity. Immediate post escape room activity evaluations indicated statistically significant improvement in participants' knowledge of principles of patient centered care. A three-month post evaluation indicated retention of the knowledge and reported increased considerations of the principles in daily.
\end{abstract}

Keywords: Allied health; Patient centered care; Interprofessional; Aboriginal health.

\section{Introduction}

Within the Northern Territory (NT), Aboriginal people represent approximately twenty-five percent of the total population (Australian Bureau of Statistics, 2016a). Within the NT public hospital services, Aboriginal people represent approximately seventy percent of patients and over fifty-eight percent live in very remote areas (Australian Bureau of Statistics, 2016b). Improving Aboriginal health and wellbeing is a crucial and complex challenge as is improving delivery of coordinated and integrated care across services (NT Aboriginal Health Plan, 2015-2018). It is also vital to acknowledge and respect the interests of Aboriginal people and their views on healthcare. This acknowledgement of values is essential to achieve equitable health outcomes. (NT Aboriginal Health Plan, 2015-2018). Patient centered care is at the core of the Top End Health Service's (TEHS) organisational culture and is clearly outlined in the Northern Territory Government. TEHS Cultural Charter (2017). There are eight principles of patient centered care as outlined in the Cultural Charter.

Figure 1. TEHS Cultural Charter Principles of Patient Centred Care

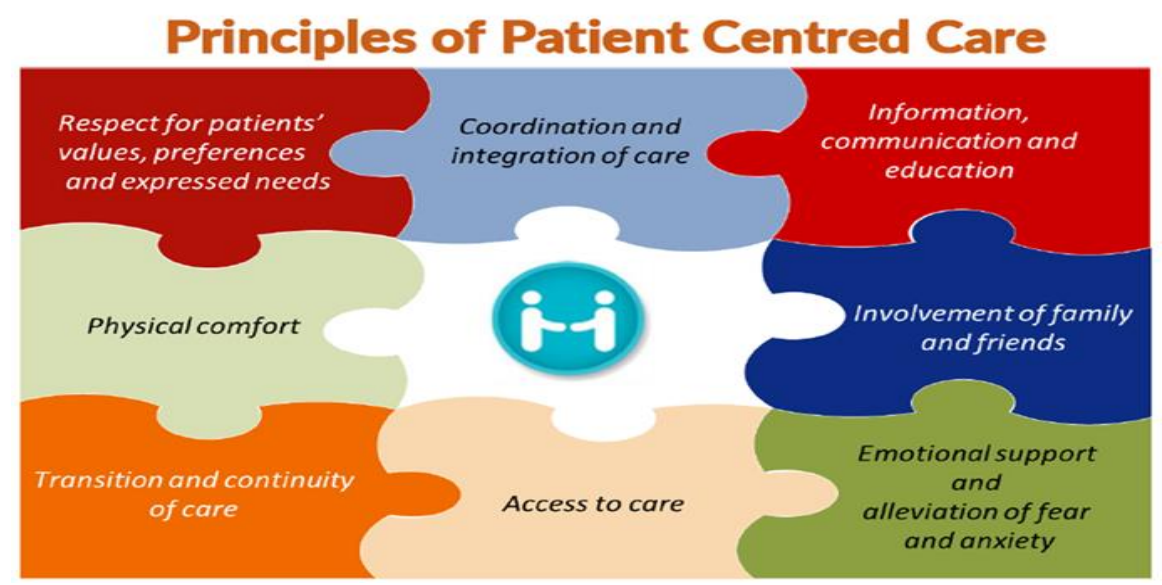


Allied health professionals play a vital role in the health outcomes of patients in the Northern Territory's Top End (Campbell et al., 2010). Many those working in remote and rural regions of the Northern Territory often work in isolation and professional silos (Campbell et al., 2010). Katherine is the third largest town in the Northern Territory, with a population of approximately 19,000 people of which forty eight percent identify as Indigenous (Australian Bureau of Statistics, 2016a). In 2019, there were nine allied health professionals based in Katherine Hospital and region and approximately seven communities based allied health professionals (Northern Territory Government Allied Health Workforce Profile, 2019). Allied health professions based permanently in Katherine include: Physiotherapy, Oral Health, Dietetics, Social Work, Pharmacy and Occupational Therapy. Visiting allied health services to Katherine region include Speech Pathology and Audiology (Northern Territory Government Allied Health Workforce Profile, 2019). In November 2019, fifty-two allied health professionals from community and children's development team joined the health service. These professionals are based in Darwin and Katherine, and provide outreach remote services. Often information on visiting allied health services, telehealth services and referral pathways for remote patients are unclear. Face to face professional development for this workforce is limited with staff relying on video conferencing into training conducted in Darwin. There was an urgent need to support this small but essential workforce with face to face professional development and encourage interprofessional practice and networking opportunities between acute and community-based professionals.

\section{Innovation}

In the last five years, commercial escape rooms have been become increasingly popular in Australia and internationally (Agarwal, 2018; Nicholson, 2015; Spira, 2019). Commercial success was then replicated in higher educational settings and professionals in healthcare began using escape rooms for professional development and student education (Adams et al., 2018; Friedrich et al., 2018; Garwood, 2019; Kutzin, 2019; Zhang et al., 2018; Zhang et al., 2019). An escape room is a live action team-based activity in which participants solve a series of puzzles and clues within a time limit (Eukel et al., 2017; Jaramillo and Trujillo, 2019; Moore and Campbell, 2019; Wu et al., 2018). It is a contemporary method to teaching content which incorporates problem-based learning and aids in the development of critical thinking skills whilst enhancing communication skills and teamwork (Brown et al., 2019; Cain, 2019; Connelly et al., 2018; Edwards et al., 2019; Hermanns et al., 2017; Jambhekar et al., 2019). Given the multigenerational allied health workforce an innovative training method run in an escape room format was selected as it incorporated inquiry-based learning thereby supporting the development of problem solving skills, and promoting team building and inference skills. The escape room learning activity was constructed on the TEHS Cultural Charter and the eight principles of Patient Centred Care. The objectives of the activity included allied health professionals in the Katherine region and those from Darwin who provide outreach services to Katherine getting to know and collaborate with each other, use effective team communication strategies, navigate barriers to communication and learn about the principles of patient centred care. Prior to commencing the escape room, the team discussed concepts such as active listening, soliciting another's perspective and negotiating a transparent plan.

\section{Method}

The escape room project was granted ethical clearance (HREC 2019-3501) and approved by the TEHS Executive Director of Allied Health, along with a budget of $\$ 50$ for materials. The case study for the escape room challenge was designed around a fictitious adult patient (Dennis) from a remote community in the NT (Borroloola) who was admitted to the Katherine Hospital. The principle of Aboriginal equality was addressed through consultation and planning with the Aboriginal Health Manager at the TEHS Clinical Learning, Education and Research Unit (CLEaRS) as well as utilisation of the Northern Territory Health Aboriginal Cultural Security Framework (2016 - 2026). The escape room activity followed Dennis's patient journey from admission, through to inpatient care and eventual discharge back to community. The case study included aspects that would be relevant to several allied health disciplines that are based in Katherine or have outreach services to Katherine and remote communities. Time required to set up the activity was five minutes and time required to complete the activity was sixty minutes. Pre-escape room activities included a 30-minute presentation to the participants on interprofessional collaboration, what an escape room is, and the principles of patient centred care. Post-escape room activities included a 15-minute group debrief session, a 10-minute video on the TEHS principles of patient centred care and completing a written individual evaluation. 


\section{Materials}

A patient file was created and included an emergency department admission report, a Modified Barium Swallow speech pathology report, an audiogram, an allergy alert form, goals of care plan and a mock-up of a panoramic dental x-ray. Two plastic lockboxes and two padlocks (a vertical resettable 4 letter word combination and a vertical resettable 3-digit number combination). The padlock combinations related directly to the case study and once opened served the purpose of providing participants with additional content to answer later questions. Clues for the patient journey, information missing from the patient file and puzzle pieces for each principle were placed in the two lockboxes. The lockboxes also contained a Webster Pak medication pack, an ultra violet torch to view the x-ray and chocolates for participants. Question and answer sheets were printed and laminated so that they could be used again thereby minimizing printing and paper costs. The items for the escape room needed to be easily transportable and easy to assemble.

Photo 1. Two lockboxes and padlocks

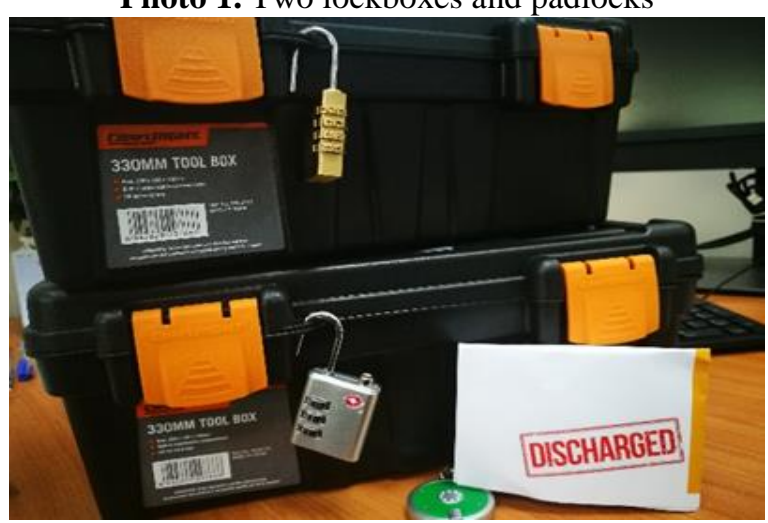

Figure 2. Room and table set-up

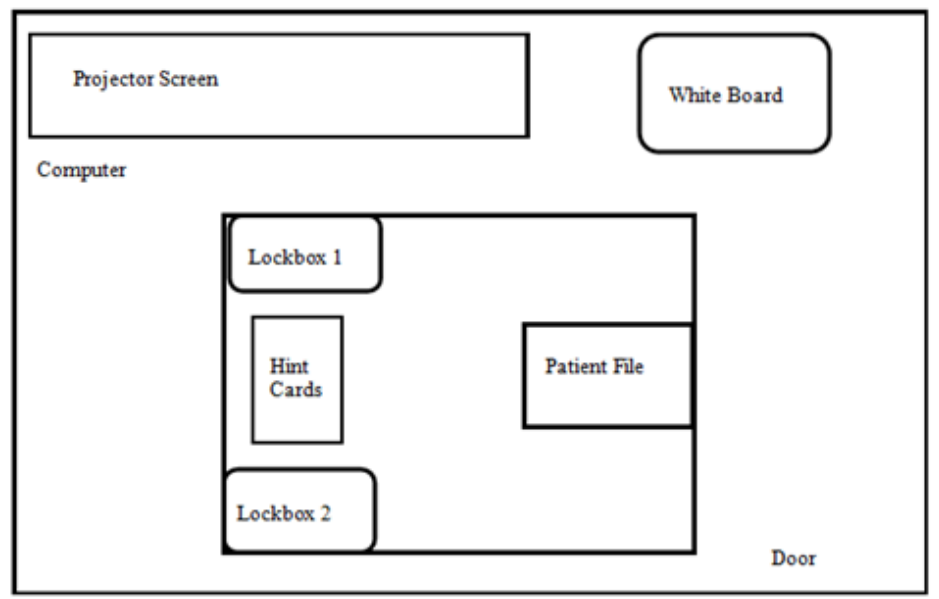

The escape room challenge was solved once all eight puzzle pieces were obtained and the discharge decision worksheet completed within the 60-minute time limit. Each principle of patient centred care had associated "hint cards" if participants required assistance. However, they had to decide as a team when to use the hint cards as they lost points for each hint card used. Each principle also had a bonus question which if answered correctly scored the team an extra point.

\section{Evaluation}

Immediately post activity the team participated in a group debrief. The debrief explored the following themes: how they felt during the activity; what lessons were learned from the challenge; how they could apply learning from the activity in the workplace; what surprised them the most; what was enjoyable / not enjoyable about the activity; and how they felt about the team communication during the activity. The group debrief provided valuable insight into allied health teamwork, collaboration across professions as well as communication strategies utilized. A written evaluation form was also utilized preintervention and post-activity with a numerical rating scale for pre-and post-patient centered care 
knowledge (1=low, $5=$ excellent) as well as an optional section for the collection of free text comments (see Appendix 1).

Additionally, a three-month post activity evaluation form was used to assess if the novelty of the activity impacted on the recall, retention and increased utilization of the principles of patient centered care in professional's daily work. The evaluation forms were based on Kirkpatrick (1998), and assessed the first two levels i.e. reaction and learning. Measurable changes in aspects of patient centered care in practice are difficult to evaluate due to a number of variables which can impact transfer of knowledge. However collaboration and communication between acute and community allied health professionals was noted by the participants themselves as improved thus meeting one of the objectives of the activity. Furthermore, the halo effect was addressed by separating the evaluation form into three sections i.e. the first evaluated participant overall experience with the type of training activity, the second evaluated knowledge of the training content pre-and post-activity and the third section which collected free text data. The use of the rating scale in assessing outcomes further reduced of the potential presence of a halo effect with the overall knowledge scores.

Table 1. Demographic characteristics of the participant population $(n=34)$

\begin{tabular}{|c|l|}
\hline Total no. participants & 34 \\
\hline Sex Male & 5 \\
Female & 29 \\
\hline Age (years) & \\
$21-29$ & 18 \\
$>29$ & 16 \\
\hline Race Non-Indigenous & \\
Indigenous Australian & 33 \\
Profession & 1 \\
Allied Health Assistant & \\
Occupational Therapy & 1 \\
Physiotherapy & 9 \\
Speech Pathology & 6 \\
Social Work & 8 \\
Oral Health & 2 \\
Dietetics & 2 \\
Pharmacy & 1 \\
Medical Imaging & 2 \\
Manager & 2 \\
\hline
\end{tabular}

Figure 3. Knowledge Levels of Principles of Patient Centred Care

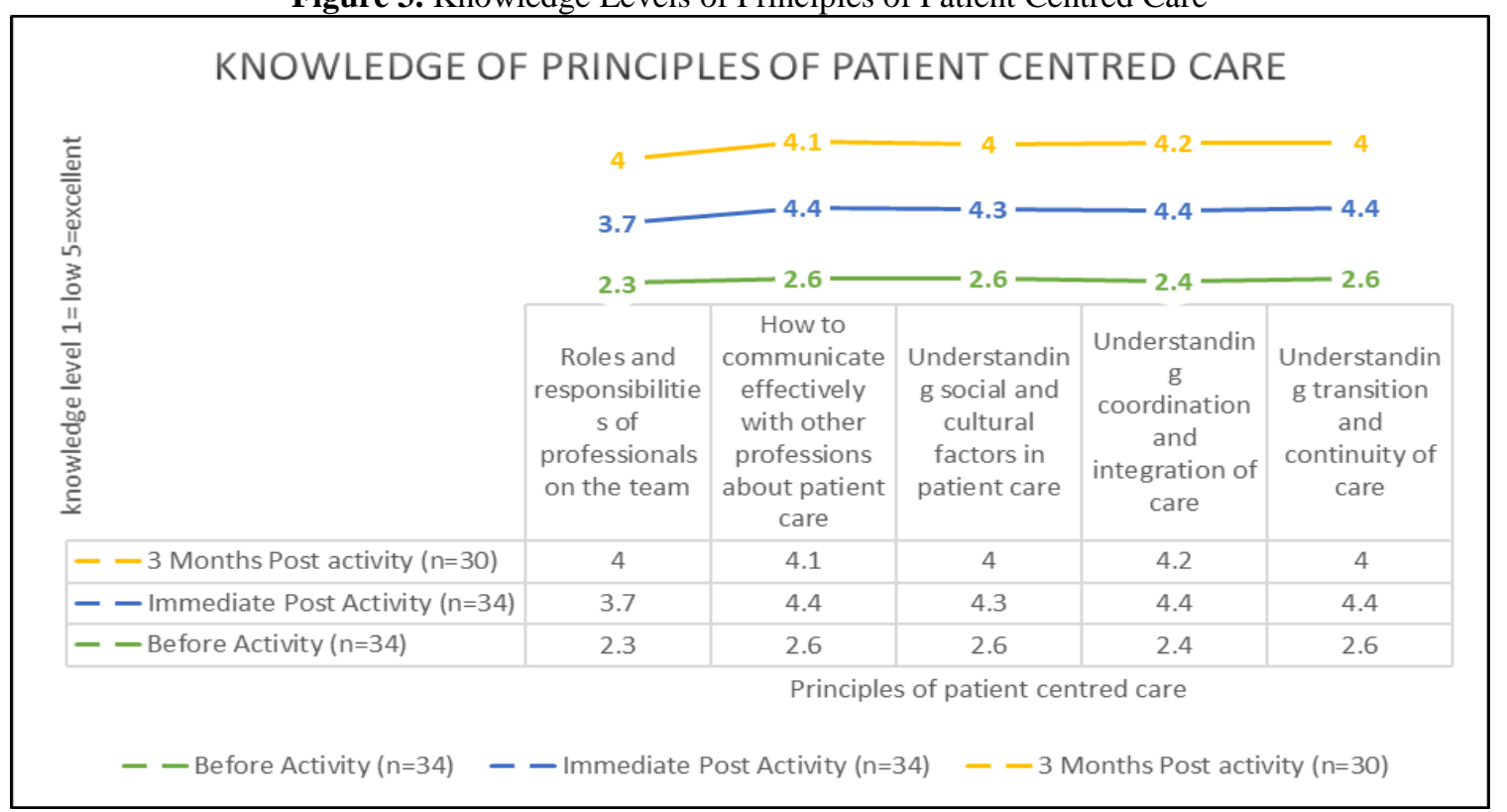


As seen in the figure above, the knowledge pre-activity mean was $2.5 \pm 0.13$, with a range of 2.3 to 2.6. The mean score immediately following the escape room activity was $4.2 \pm 0.30$, with a range of 3.7 to 4.4. There was an increase in the overall mean scores from pre-assessment to immediate postassessment. A paired sample t-test was conducted to evaluate the impact of the activity on participant knowledge level scores. There was a statistically significant increase in knowledge level scores from pre activity to post activity $(t=17.09$, two tailed $p<0.0001)$. This difference is considered to be statistically meaningful and shows strong evidence that the escape room activity improved knowledge of patient centered care, on average, by approximately 1.8 points.

All participants felt that this exercise enhanced interprofessional skills and facilitated teamwork and collaboration. Thirty of the original thirty-four participants completed the three-month post evaluation with a mean score was 4 and a standard deviation of 0.1 , thus the recall of information three months post activity for those participants remained high.

Participants were enthusiastic about the type of learning activity for their professional development as evidenced in the narrative responses below:

- "Very good use of escape room to create an interactive learning environment."

- "Lots of room for participation and reflection."

- "Thoroughly enjoyed the escape session"

- "I think about the activity and the principles when I see patients now."

\section{Outcomes}

This study was the first to investigate recall of information three months post escape room activity. Further research is required to evaluate longer term impact on interprofessional patient centered care through monitoring of referrals within allied health professions and utilization of specialist outreach and tele health services in the Katherine region.

Limitations of this project include the lack of a control group that would have received the patient centered information through traditional training methods for comparison of knowledge retention outcomes. However, in summary participants found the interactive nature of the activity highly engaging and effective. Allied health professionals were able to collaborate, communicate and review patient information as a team which met the objectives of the workshop. The TEHS Organizational Cultural Charter states that "The people, populations and communities we serve are our first priority". This activity exemplified the above statement by bringing patient centered care to the forefront in a novel manner to establish a skilled and culturally reflective allied health workforce.

\section{What's next?}

It is anticipated that the success of "Discharging Dennis" can be replicated with a paediatric case study escape room currently under development. It is proposed to have a suite of allied health case studies and a facilitator guide developed in 2020. This will enable clinical educators who are interested in conducting escape room activities within existing courses to easily incorporate this type of breakout activity into lesson plans. By reducing silos through interprofessional practice and promoting integration of healthcare this activity has shown the potential for training in a variety of settings with multiple health professionals as it encourages understanding of individual roles on teams and interprofessional trust.

\section{Acknowledgements}

The researchers would like to acknowledge Ester-Rose Seaton, TEHS Aboriginal Health Manager for her valuable insights and contribution to the authenticity of the case study.

\section{Conflict of Interest}

The authors declare no conflict of interest.

\section{References}

Adams, V., Burger, S., Crawford, K. and Setter, R. (2018). Can you escape? Creating an escape room to facilitate active learning. Journal for Nurses in Professional Development, 34(2): E1-E5.

Agarwal, P. (2018). State of the Escape room Industry report, Owners Survey. Available at; https://seoorb.com/state-of-escape-room-industry-survey/.

Australian Bureau of Statistics (2016a). National Aboriginal and Torres Strait Islander Social Survey, 2014-15. ABS cat. No. 4714.0. Canberra: ABS. Viewed 16 December 2019, Available at: http://www.abs.gov.au/AUSSTATS/abs@.nsf/DetailsPage/4714.02014-15. 
Australian Bureau of Statistics (2016b). Katherine Region data Summary, 2014-15. Canberra: ABS. Viewed 16 December 2019, Available at: https://itt.abs.gov.au/itt/r.jsp?RegionSummary\&region=70205\&dataset=ABS_REGIONAL_ASG S\&geoconcept=REGION\&datasetASGS=ABS_REGIONAL_ASGS\&datasetLGA=ABS_NRP9_ LGA\&regionLGA=REGION\&regionASGS=REGION.

Brown, N., Darby, W. and Coronel, H. (2019). An Escape Room as a Simulation Teaching Strategy. Clinical Simulation in Nursing, 30: 1-6.

Cain, J. (2019). Exploratory implementation of a blended format escapes room in a large enrolment pharmacy management class. Currents in Pharmacy Teaching and Learning, 11(1): 44-50.

Campbell, N., Smedts, A., Lowe, S., Keane, S. and Smith, T. (2010). The Northern Territory allied health workforce study: Final Report. Darwin: Northern Territory Clinical School; Available at: http://www.flinders.edu.au/medicine/fms/sites/northern_territory_clinical_school/documents/Rese arch\%20Publications/The\%20Northern\%20Territory\%20Allied\%20Health\%20Workforce\%20Stu dy.pdf.

Connelly, L., Burbach, B. E., Kennedy, C. and Walters, L. (2018). Escape room recruitment event: Description and lessons learned. Journal of Nursing Education, 57(3): 185-89.

Edwards, T., Boothby, J. and Succheralli, L. (2019). Escape Room: Using an Innovative Teaching Strategy for Nursing Students Enrolled in a Maternity Clinical Course. Teaching and Learning in Nursing, 14: 251-53.

Eukel, H. N., Frenzel, J. E. and Cernusca, D. (2017). Educational Gaming for Pharmacy Students - Design and Evaluation of a Diabetes-themed Escape Room. American Journal of Pharmaceutical Education, 81(7): 1-5.

Friedrich, C., Teaford, H., Taubenheim, A., Boland, P. and Sick, B. (2018). Escaping the professional silo: an escape room implemented in an interprofessional education curriculum. Journal of Interprofessional Care: 1-3.

Garwood, J. K. (2019). Escape! Using an Escape Room to Promote Active Learning and Clinical Outcomes. Sigma Congress. Available at: https://stti.confex.com/stti/congrs19/webprogram/Paper95312.html.

Hermanns, M., Deal, B., Hillhouse, S., Opella, J. B., Faigle, C., Campbell, I. V. and Robert, H. (2017). Using an" Escape Room" toolbox approach to enhance pharmacology education. Journal of Nursing Education and Practice, doi:10.5430/jnep.v8n4p89:

Jambhekar, K., Pahls, R. P. and Deloney, L. A. (2019). Benefits of an Escape Room as a Novel Educational Activity for Radiology Residents. Academic radiology. doi: 10.1016/j.acra.2019.04.021.

Jaramillo, R. S. X. and Trujillo, M. A. (2019). The learning behind the escape room. Med Teach, 1. doi:10.1080/0142159x.2019.1654090 (ePub - Aug 26 2019).

Kirkpatrick, D. L. (1998). Evaluating Training Programs: The Four Levels 2nd Edition. Berrett-Koehler Publishers. Oakland.

Kutzin, J. M. (2019). Escape the Room: Innovative Approaches to Interprofessional Education. Journal of Nursing Education, 58(8): 474-80.

Moore, L. and Campbell, N. (2019). Novel interprofessional learning for healthcare students: An escape room pilot. Focus on Health professional Education: A multi-professional journal, 20(1): 1-7.

Nicholson, S. (2015). Peeking Behind the Locked Door: A Survey of Escape Room Facilities. White Paper Available at http://scottnicholson.com/pubs/erfacwhite.pdf.

Northern Territory Government Allied Health Workforce Profile (2019). Darwin: Top End Health Service. Internal Document.

Northern Territory Government. TEHS Cultural Charter (2017). Darwin: Top End Health Service. Internal Document.

Spira, L. (2019). 5 Year US Escape Room Industry Report. https://roomescapeartist.com/2019/08/08/5year-us-escape-room-industry-report-august-2019/.

Wu, C., Wagenschutz, H. and Hein, J. (2018). Promoting leadership and teamwork development through Escape Rooms. Medical Education, 52(5): 561-62.

Zhang, X. C., Diemer, G., Lee, H., Jaffe, R. and Papanagnou, D. (2019). Finding the 'QR'to Patient Safety: Applying Gamification to Incorporate Patient Safety Priorities Through a Simulated 'Escape Room'Experience. Cureus, 11(2): 1-11.

Zhang, X. C., Lee, H., Rodriguez, C., Rudner, J., Chan, T. M. and Papanagnou, D. (2018). Trapped as a Group, Escape as a Team: Applying Gamification to Incorporate Team-building Skills Through an "Escape Room" Experience. Cureus, 10(3), e2256 